\title{
Living in Stillness, the Experience of Men with Spinal Cord Injury in the First Five Years after the Injury- A Content Analysis Study
}

\author{
Adel Mir1, Mozhgan Rahnama², Mahin Naderifar³, Mahin Badakhsh \\ ${ }^{1}$ Student Research Committee, Faculty of Nursing and Midwifery, Zabol University of Medical Sciences, Zabol, Iran. \\ ${ }^{2}$ Department of Nursing, Zabol University of Medical Sciences, Zabol, Iran. ${ }^{3}$ Department of Nursing, Faculty of Nursing \\ and Midwifery, Zabol University of Medical Sciences, Zabol, Iran. ${ }^{4}$ Department of Midwifery, Faculty of Nursing and \\ Midwifery, Zabol University of Medical Sciences, Zabol, Iran.
}

\section{ABSTRACT}

\section{BACKGROUND}

Spinal cord injury (SCI) is an experience that changes not only the path of life of the SCI person, but also the life of the spouse, parents, and children of the injured person. Considering that SCI imposes a significant burden on the healthcare system, the aim of the present study was to explain the experiences of SCI men within the first 5 years after the injury.

\section{METHODS}

The present qualitative study was carried out based on conventional content analysis. Data were collected through in-depth and semi-structured interviews with male SCI patients. The participants were selected using purposive sampling and data saturation was achieved after 8 interviews so that no new finding was added. The recorded interviews were transcribed verbatim. Data analysis was performed simultaneously, and content analysis was used to reduce the data, name the data, obtain analytical codes, and finally identify themes. Peer review and finding verification methods were used to ensure rigor of the data.

\section{RESULTS}

Analysis of the findings led to emergence of 4 themes, including going through wide range of suffering, negligence of needs and achieving regrets, relief of the suffering, adaptive paradoxical reactions and 12 sub-themes.

\section{CONCLUSIONS}

Investigation of the first-5-year experiences of SCI patients showed that, following injury, the life of these patients is in a kind of stillness due to a wide range of suffering, exposure to unmet needs, staying in regrets of regaining health, and reactions that rather than being constructive are sometimes destructive. Therefore, living in stillness can be considered as an extract of the experience of SCI patients in the first five years after the injury.

\section{KEY WORDS}

Men, Patients with Spinal Cord Injury, First Five Years after the Injury, Qualitative Research
Corresponding Author:

Mozhgan Rahnama,

Department of Nursing,

Zabol University of Medical Sciences,

Zabol, Iran

E-mail: morahnama0@gmail.com

DOI: 10.14260/jemds/2019/701

Financial or Other Competing Interests: None.

How to Cite This Article:

Mir A, Rahnama $M$, Naderifar $M$, et al. Living in stillness, the experience of men with spinal cord injury in the first five year after the injury- a content analysis study. J. Evolution Med. Dent. Sci. 2019;8(43): 3234-3239,

DOI:

Submission 02-09-2019,

Peer Review 11-10-2019,

Acceptance 18-10-2019,

Published 28-10-2019. 


\section{BACKGROUND}

Spinal cord injuries (SCIs) are among the most damaging injuries experienced by an individual.(1) The average global statistics of SCI cases is between 20-50 people per million populations per year.(2) According to the National Spinal Cord Injury Statistics Center (NSCISC), approximately 27000 SCI individuals live in the United States, and approximately 12000 new injuries occur each year.(3) According to reliable sources, there are 70000-90000 SCI patients in Iran.(1) More than 3000 people suffer from SCI in the country each year ( $84 \%$ due to trauma and accidents and $16 \%$ due to spinal cord diseases).(4) This complication occurs more frequently in men $(\sim 80 \%)$ than in women, ${ }^{(5)}$ as men are usually involved in high-risk sports and physical activity jobs.(6) Basically, half of the new annual SCIs occurs among young people aged 15-30 years.(5). Studies have shown that SCI is a complex health condition associated with numerous problems $(7)$ and may affect patients' quality of life in addition to physical, psychological, personal, and emotional problems.(8) Obviously, living with SCI is a complex process that requires adaptation to physical, mental changes, and social performance for the affected individuals and their families.(1) Basically, SCI is an experience that not only changes the path of life of the affected person, but also that of his/her spouse, parents and children.(2) In addition, physical and motor disabilities cause a great deal of damage in terms of production and social costs.(9) Activities that seem easy for healthy people are difficult for these people. These people face numerous problems every day such as financial problems, lack of social support, and health problems.(10) One of the most important problems of SCI patients after an acute period is employment and return to the labour market.(11) In a study of physically disabled patients, Pashaei Sabet et al., showed that the needs of these clients included being supported by others, including family and community, continued care throughout the disability period, and the need for independence. ${ }^{(12)}$

Overall, considering the high numbers of SCI men, a wide range of problems, lack of studies in this area, and the fact that SCI imposes a significant burden on the healthcare system within the first 5 years after the injury, ${ }^{(13)}$ and since investigating the experiences and knowledge of the issues faced SCI individuals while going through the crisis is essential for the proper organization of conditions, ${ }^{(8)}$ and quantitative research methods lack capacity and capability needed to address such issues, qualitative content analysis is one of the methods of knowing and explaining the dimensions of a concept based on the context in which a phenomenon occurs (Elo \& Kigas, 2008). Qualitative content analysis allows researchers to interpret the data authenticity subjectively but using a scientific method. The aim of the content analysis study is to offer a knowledge of the experience related to a particular phenomenon that provides a deeper understanding of the phenomenon under study (Krippendorf, 2004; Hsieh \& Shannon, 2005). A qualitative study will be one of the most appropriate methods for achieving better and more comprehensive understanding of patients' experiences in the social and cultural context of the country. Considering the scant evidence available in the present studies, the aim of this study was to explore the experiences of SCI men in the first 5 years after the injury using content analysis approach. It is hoped that this study can provide a guide for implementing treatment strategies for the treatment team by providing a clear picture of human experiences.

\section{METHODS}

The present qualitative study was conducted using conventional content analysis approach. We investigated the experiences of eight male SCI patients who had been suffering from the disease for five years and had a case at Zabul City Welfare and Rehabilitation Center were using purposive sampling. Participants included Persian-speaking SCI patients who volunteered or content to participate in the study and had been suffering from SCI for 5 years. Exclusion criteria included hearing or speech problems and the person's unwillingness or inability to participate in the study. Sampling was carried out after obtaining Ethical approval from Zabol University of Medical Sciences and receiving a written introduction letter from the university and coordinating with authorities of the Welfare and Rehabilitation Center. All participants participated in the study with informed consent. Participants were assured that all their personal information will be kept confidential when publishing the results. The place and time of the interview were determined as agreed by the participants. Data collection was carried out by a researcher referring to the Welfare and Rehabilitation Center and patients' homes after coordinating with them and obtaining their permission. At first, the aim of the research was explained to them, and then the sampling was continued until data saturation. The criterion for achieving data saturation was the lack of access to new concepts and codes in subsequent interviews. Subthemes and themes related to the aim of this study were saturated after interviewing with eight participants, and no new data were generated. The data collection method included semi-structured in-depth interviews using openended questions, including, "Talk about your experiences after SCI? What has changed in your life after SCI?" During the interview, the researcher helped participants share their experiences without directing the conversation. Probing questions were also used if necessary. Interviews were conducted in a quiet environment. Each interview lasted 4560 minutes in one or two sessions depending on the participants' condition. All interviews were recorded, recorded verbatim, reviewed, coded, and immediately analysed by the researcher. In fact, data analysis was performed simultaneously and continuously with data collection. Data were analysed using conventional content analysis approach in a way that each interview was first read carefully for obtaining an initial grasp, important statements were underlined, and recorded as codes (Initial coding). The participants' own words and implicating codes (researcher's perceptions of the statements) were used for initial coding. Then, codes that were conceptually similar to each other were modified and subdivided into categories and subcategories to clarify meaning. The data analysis process was performed according to the steps of Graneheim and Lundman.(14) In order to meet credibility, the coded interviews were given to the participants to confirm that they match with their experiences, and corrections were made in 
some cases. In order to meet the trustworthiness criterion the codes and concepts obtained were consulted with and investigated by the experts and colleagues of the research project. Maxqda version 12 used for entering, categorize and analysis of data. Moreover, several colleagues were asked to code some parts of the transcript of the interviews and then review the degree of agreement for coding. To confirm the transferability of the findings, attempts were made to select participants with different demographic characteristics and different experiences and the researcher assessed all aspects of behaviour, events, and living experiences.

The confirmability of findings was met by the detail-rich descriptions of all stages of the research, while the details of the research were carefully documented to allow the evaluation of external observers. The following ethical consideration were also taken into account: obtaining an introduction letter, obtaining informed consent from the participants for recording interviews, confidentiality of information, and allowing them to withdraw from the study.

\section{RESULTS}

The individual characteristics of the participants are presented in Table 1 . The data analysis resulted in the extraction of 4 categories and 12 subcategories (Table 2).

\begin{tabular}{|c|c|c|c|c|c|c|c|}
\hline 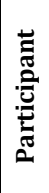 & 总 & $\frac{n}{\sum^{n}}$ & 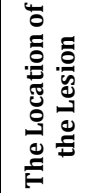 & 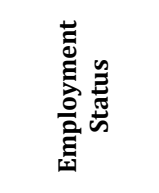 & 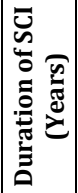 & 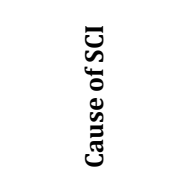 & 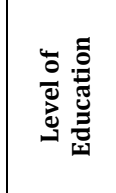 \\
\hline P.1 & 37 & Married & Cervical & Unemployed & 2 & Accident & Elementary \\
\hline P.2 & 40 & Married & Cervical & Teacher & 4 & Accident & Bachelor \\
\hline P.3 & 29 & Married & Lumbar & Unemployed & 3 & Accident & Diploma \\
\hline P.4 & 22 & Single & Lumbar & Unemployed & 3 & Accident & Cycle \\
\hline P.5 & 28 & Single & Chest & Unemployed & 2 & Accident & Diploma \\
\hline P.6 & 38 & Single & Cervical & Unemployed & 1 & Fall from a height & Diploma \\
\hline P.7 & 57 & Married & Cervical & Manual worker & 2 & Fall from a height & Illiterate \\
\hline P.8 & 41 & Single & Lumbar & Unemployed & 4 & Accident & Diploma \\
\hline \multicolumn{8}{|c|}{ Table 1. Individual Characteristics of Participants } \\
\hline
\end{tabular}

\begin{tabular}{|c|c|c|}
\hline \begin{tabular}{c|} 
Main \\
Theme
\end{tabular} & Themes & Subthemes \\
\hline \multirow{5}{*}{$\begin{array}{l}\text { Living in } \\
\text { stillness }\end{array}$} & $\begin{array}{l}\text { Going through a wide } \\
\text { range of sufferings }\end{array}$ & $\begin{array}{l}\text { Physical suffering, Hospitalization suffering, } \\
\text { Dependence-induced suffering, Economic } \\
\text { suffering, Emotional suffering, Family suffering }\end{array}$ \\
\hline & $\begin{array}{c}\text { Negligence of needs and } \\
\text { achieving regrets }\end{array}$ & Seeking needs, achieving regrets \\
\hline & Pain relief & $\begin{array}{c}\text { Relying effect of spiritual beliefs, Relying effect of } \\
\text { support }\end{array}$ \\
\hline & \multirow{2}{*}{$\begin{array}{l}\text { Adaptive paradoxical } \\
\text { reactions }\end{array}$} & $\begin{array}{l}\text { Constructive reactions (Striving for adaptation, } \\
\text { self-care, return to life) }\end{array}$ \\
\hline & & \begin{tabular}{|c}
$\begin{array}{c}\text { Destructive reactions (Aggression, Isolation, } \\
\text { denial of disability, crying, moping ) }\end{array}$ \\
\end{tabular} \\
\hline
\end{tabular}

\section{Going through a Wide Range of Sufferings}

The experiences of SCI men showed that they often experience different types of sufferings, including physical suffering, hospitalization suffering, dependence-induced suffering, economic suffering, emotional suffering, and family suffering.

\section{Physical Suffering}

Post-SCI physical problems in participants may include sleep disturbance, pain, immobility, urinary and stool incontinence, constipation, instability, bed wounds, paresis, arthritis, impotence, kidney disease, and urine infection.

"I've had urinary and faecal incontinence since I severed my spinal cord, and I'm using diapers, it's hard to say let alone bearing it, it's very hard". (M. 37 years old with cervical injury)

\section{Hospitalization Suffering}

Patients had experienced difficulties, including prolonged hospitalization, loss of consciousness, undergoing prolonged surgeries, pain, exposure to surgical complications, poor caregiving care, exposure to frustrating talks of physicians, and observation of critically ill patients in ICU following the injury and hospitalization.

"When I was hospitalized, I was not well taken care of, so I suffered from bedsore" (M. 57 years old with cervical injury)

\section{Dependence-Induced Suffering}

SCI make them dependent in various fields, including financial, self-care, mobility, and etc.

"My living conditions are very different from when I was healthy. I used to work and make a living myself and I didn't need anyone, but now I need others "(M. 38-year-old with a cervical injury).

\section{Economic Suffering}

These patients experience a lot of sufferings while paying for SCI-associated medical and living expenses due to the cost of treatment on the one hand, and the insufficient financial support of the organizations concerned, on the other hand.

"I as a disable person cannot afford the up-to-date facilities available to disabled people because it costs a lot of money." (M. 41 years old with lumbar injury)

\section{Emotional Suffering}

Following SCI, these patients experienced annoying feelings such as guilt, nostalgia, misery, jealousy, feeling like a burden, embarrassment, hopelessness, fatigue, disgust with life, and loneliness.

"I get embarrassed when using a wheelchair because people are hurting me with their look, and they feel pity for me and I don't want to them feel for me." (M. 22 years old, lumbar injury)

\section{Family Suffering}

Experiences of SCI men showed that it has profound effects on family well-being, comfort, and economic status, and the patient feels pain while seeing these negative effects on the family.

"My family suffered a lot because of my spinal cord injury. My wife and children were left unattended for the whole twenty days I was hospitalized." (M. 40 years old, cervical injury)

\section{Negligence of Needs and Achieving Regrets}

Based on the experiences of SCI men, they have experienced unmet needs and have sought to satisfy them, and have a lot of regrets. 


\section{Seeking Needs}

Following the onset of the injury, patients experienced the need to seek family support and social support resources for self-care, continued treatment, and financial troubles. "My friend used came over to me before my SCI, but now when I am confined to the home, my friends come over to me less frequently and I feel lonely because I like to see many people at home."

"We need media officials to state our problems (SCI patients) and scrutinize how they can be resolved." (M. 41 years old, lumbar injury)

\section{Achieving Regrets}

SCI has caused patients to have regrets, such as inability to play roles, inadequate access to quality medical aids, problems left largely unaddressed by the authorities, comparing the present situation with the past, remembrance of past healthy days, feeling envy about the healthy status of others, lack of health, job loss, and tolerance of being confined to the home.

"I feel so sad since I sit on a wheelchair and remember those happy and healthy days." (M. 57 years old, cervical injury)

\section{The Relief of Suffering}

Investigation of the experiences of SCI men revealed that despite their suffering, they felt somewhat relieved by having spiritual beliefs and receiving support from family members, medical team, and welfare center staffs.

\section{Relieving Effect of Spiritual Beliefs}

Some SCI patients have accepted and coped with difficult conditions because of their spiritual beliefs and beliefs such as trusting in God and the Ahl al-Bayt, being pleased with God's willing, believing in divine fate, and being hopeful in God's favor.

"When I was in ICU, I didn't know what was going on and I couldn't move my neck, but I was able to maintain my spirit because I trusted in God." (M. 40 years old, cervical injury)

\section{Relieving Effect of Support}

Some SCI patients stated that support provided by family members, spouses, and related organizations played an important role in alleviating their sufferings.

"Since I served my spinal cord, my wife is my nurse and takes care of me by all means." (M. 37 years old, cervical injury)

\section{Adaptive Paradoxical Reactions}

The experiences of SCI men have shown that despite their inability to move, they have shown reactions to tolerate the conditions ahead, some of which were constructive, and some were not only destructive, but had devastating effects.

\section{Constructive Reactions}

Some patients have struggled for adaptation, self-care, and return to life, reflecting their constructive reactions to adapting to new conditions.

"Since I served my spinal cord, I have been staying home for two years, but one day I decided to solve this problem for myself and no longer imagine myself as a disabled person. I told myself I believed that if I'm not physically stronger than a healthy person, I'm not weaker. "(M. 41 years old with lumbar injury)

\section{Destructive Reactions}

Some other SCI patients also referred to some reactions such as depression, isolation, denial of disability, crying and moping, which indicate their inability to adapt to the new conditions.

"Before I had served my spinal cord, I participated in all weddings and sad ceremonies, but now I've been confined to my home for five years and I haven't gone anywhere." (M. 57 years old with cervical injury)

\section{DISCUSSION}

The experiences of SCI men showed that approximately all of them have experienced different types of suffering, including physical suffering, hospitalization suffering, dependence suffering, economic suffering, emotional suffering, and family suffering. Many studies have reported SCI patient had tolerated these wide range of sufferings. As, Metabing et al. referred in a study to dependence-induced suffering as one of the themes extracted from the experiences of SCI patients. (15) In a qualitative study of SCI patients, they felt physical fatigue over time and were forced to become dependent (Bodil Bjornshave Noe et al. (2014).(8) Also, Hosseini Golafshani et al. (2013) stated that the first years of SCI is very difficult and challenging, such as the arrival of a person into a new world they had not previously imagined, and are completely dependent on others in this new world.(4) In a qualitative study on patients with physical disabilities, Pashaei Sabet et al. also referred to independence as one of the themes achieved.

In the affirmation of the suffering imposed to the family of SCI patients, Toolabi and Ghanbari (2015) write that disability affects not only the disabled person but also the family system in different dimensions, the usual interactive pattern between family members is disrupted and family members face with stress and new roles.(9) Nikbakht Nasrabadi et al. (2017) also showed in their qualitative study that the essence of experience of SCI clients' spouses included being support in a context of limitations. They also stated that the spouses of these patients face numerous limitations and challenges and family empowerment has been proposed.(16)

Concerning emotional suffering, the results of Metabing et al.'s qualitative study suggest emotional experiences including guilt, loneliness, frustration, and futility in SCI patients.(15) In a qualitative study on men with physical and motor injuries, Ardani et al. showed that participants had a sense of inferiority, feeling like a burden, and being futile due to being financially dependent on their family.(17)

In confirming the physical suffering of SCI patients, Sedghi Gouy Aghaj et al. write that pain is the worst and most debilitating problem among SCI patients as they may experience one or more types of pain at the same time.(5) All SCI participants raised complaints about economic suffering due to the high cost of treatment on the one hand, the loss of a previous job due to physical disabilities, and the inability to work in a job proportionate to their physical condition, on the 
other hand. In the confirmation of this statement, in a qualitative study on men with physical and motor injuries, Ardani et al. also referred to therapeutic issues and occupational concerns as the two themes obtained. These men were upset since they had to pay heavy costs for the treatment of physical problems. In addition, most participating men had severe anxiety about their inability to pay for living expenses due to the lack of a permanent job with an income commensurate with the living expenses of a disabled person.(17) Nikkhah \& Fadaei (2016) also concluded in their study that economic needs were one of the dimensions of the disabled people's needs and emphasized their other needs, including employment, housing, and allowance.(18)

The experiences of SCI men showed that some of them have experienced the need for family support and social support resources and have attempted to resolve them and have had a great deal of regret. Pashaei Sabet et al. showed in their qualitative study on patients with physical disability that the need to be supported was one of the themes obtained.(12) Nikbakht Nasrabadi et al. also concluded that exposure of SCI patients with to social constraints, including inadequate and delayed insurance coverage and inadequate facilities at societal level and emphasized the need to eliminate them(19) Nikkhah \& Fadaei (2016), while identifying the social dimension of the disabled people's needs, emphasized the SCI patients' right to have access to insurance services and the presence of appropriate staffs in welfare center and other disability related organizations. ${ }^{(18)}$ Hosseini Golafshani et al. also emphasized the important role of relatives in helping SCI patients adapt to new conditions.(4)

Investigation of the experiences of SCI men revealed that despite their sufferings, they felt somewhat relieved by having spiritual beliefs and family support, medical team and staffs at welfare center. Consistent with this result, Rahmani Rasa et al. (2017) introduced spirituality and social support from family and friends as important facilitators in helping these patients adapt to new conditions.(20) The influential supportive role of the family in the Nikbakht Nasrabadi et al.'s study has also been identified as and factor facilitating the recovery of SCI patients.(19)

Babamohammadi et al. also reported in the qualitative study that SCI patients used spiritual beliefs as an adaption strategy.(1) One of the themes obtained in the qualitative study of Ardani et al. included the spiritual beliefs and the participants pointed out that they had been able to accept the disability and the subsequent difficulties because they had considered SCI to be God's will and wisdom.(17)

Experiences of SCI men have shown that they have shown paradoxical reactions, in the face of disability, to adapt to the conditions ahead and some of these reactions were constructive, but some of them were not only nonconstructive but also had destructive impacts. These paradoxical reactions are rooted in the acceptance or rejection of SCI-induced disability. In a qualitative study, Babamohammadi et al., also revealed that SCI patients made efforts to achieve independence and self-care in order to adapt to the new conditions.(1) In a study on experiences of veterans, Toolabi et al. (2015) also showed constructive reactions such as acceptance of the new situation and resumption of social activities.(9) Tagaki also demonstrated in their qualitative study that SCI men attempted to live like healthy people and find the positive aspects of their lives.(21) In justifying the non-constructive reactions of SCI patients, Barari and Ghafari write disability exists not only in the body of the disabled persons but also in their mindsets and attitudes to the extent that disabled individual experience discontinued relationships, and social isolation due to inability to change their lifestyles.(22) Ebadollahi et al. (2001) also suggested that the views and attitudes of society and healthy people towards disabled people cause them to experience social stigmas, which implicating their inability and incapacity, and in turn cause them to feel futile and worthless, and inappropriate pity can also lead to feelings of inadequacy, dependence, inferiority or even anger.(23) Nurses can play an important role in providing appropriate context for appropriate supportive measures that enable them to manage the problems facing these patients by paying special attention to consequences of confronting disability in SCI patients.(24) This study has been carried out as qualitative limited study. Therefore, as with all qualitative studies, the generalizability is limited, and the study needs to be repeated elsewhere with different cultural conditions.

\section{CONCLUSIONS}

Investigation of the first-5-year experiences of SCI patients showed that the incidence of this injury has caused them to undergo a wide range of suffering (physical suffering, hospitalization suffering, dependence-induced suffering, economic suffering, emotional suffering, and family suffering), thus leading them to meet new needs arising from their disability and to regain their health. However, family support along with patients' spiritual beliefs play an important role in alleviating their suffering. Eventually, however, these patients exhibit paradoxical reactions in the face of severe disability, depending on acceptance or rejection of the disability. Some of these reactions are constructive but others are destructive. Overall, the end product of these reactions appears to be insufficient to advance the lives of these patients and this life is in a state of stillness due to a wide range of suffering, facing unmet needs, staying in regrets of regaining health, and reactions that are sometimes destructive rather than constructive. Therefore, living in a state of stillness can be considered as an extract of the experience of SCI patients in the first 5 years after the injury.

\section{ACKNOWLEDGEMENT}

This article is the result of a master's thesis in internalsurgical field from the Faculty of Nursing, Zabol University of Medical Sciences, with the code of ethic of IR.ZBMU.REC.1397.169. The authors of the article would like to express their thanks to the Zabol University of Medical Sciences, the patients and all those who helped them in this research. 


\section{REFERENCES}

[1] Babamohamadi H, Negarandeh R, Dehghan-Nayeri N. Coping strategies used by people with spinal cord injury: a qualitative study. Spinal Cord 2011;49(7):832-7.

[2] Abdolahi M. Evaluation of quality of life in patients with spinal cord injury following the Bam earthquake in 2003. 2016;3(2):1-7.

[3] Dillaway HE, Lysack CL. Most of them are amateurs: Women with spinal cord injury experience the lack of education and training among medical providers while seeking gynecological care. Disability Studies Quarterly 2015;35(3).

[4] Abedi H, Ahmadi F. Reflection on the experiences of disabled people: the society as a cause of growth or barrier. Journal of Qualitative Research in Health Sciences 2013;2(3):248-60.

[5] Goyaghaj SN, Khoshknab FM, Alamdarlo A, et al. Effect of exercise program on visceral pain intensity in patients with paraplegia spinal cord injury: a randomized controlled trial. Scientific Journal of Hamadan \& Midwifery Faculty 2017;25(3):17-25.

[6] Samuel VM, Moses J, North N, et al. Spinal cord injury rehabilitation: the experience of women. Spinal Cord 2007;45(12):758-64.

[7] Rubinelli S, Glässel A, Brach M. From the person's perspective: perceived problems in functioning among individuals with spinal cord injury in Switzerland. Journal of Rehabilitation Medicine 2016;48(2):235-43.

[8] Noe BB, Bjerrum M, Angel S. The beginning of a new life following traumatic spinal cord injury-patient's experiences one month post-discharge. International Journal of Physical Medicine and Rehabilitation 2015;3(1):e.

[9] Tolabi Z, Ghanbari F. Veterans' life experiences: a phenomenological study. Journal of Qualitative Research in Health Sciences 2015;4(3):266-79.

[10] Hosseini H. The survey of quality of life of spinal cord injured people in Yazd in 2014. Military Caring Sciences Journal 2015;1(2):88-98.

[11] Fatehi F. Perceived experiences of unemployed people with spinal cord injury in the process of returning to work. J Res in Rehab Sci 2011;8(2).

[12] Sabet PF, Tabrizi NK, Khankeh H, et al. Rehabilitation needs of patients with physical disabilities due to traffic accidents for returning to the community: a qualitative study. Iranian Journal of Rehabilitation Research in Nursing (IJRN) 2014;1(1):74-87.
[13] Dryden D, Saunders LD, Rowe BH, et al. Utilization of health services following spinal cord injury: a 6-year follow-up study. Spinal Cord 2004;42(9):513-25.

[14] Graneheim UH, Lundman B. Qualitative content analysis in nursing research: concepts, procedures and measures to achieve trustworthiness. Nurse Education Today 2004;24(2):105-12.

[15] Mothabeng DJ, Malinga CP, Van der Merwe C, et al. The views of patients with spinal cord injuries on their rehabilitation experience. South African Journal of Physiotherapy 2007;63(3):22-5.

[16] Nikbakht A, Gomarverdi S, Bastami A, et al. Spouses' experiences of living with patients with spinal cord injuries: a phenomenological study. Iran J of Nurs Res 2017;12(3):24-35.

[17] Ardani AS, Tazerjan SA, Fattahi G. Explaining the lived experience of men with physical-motor injury in marriage: a phenomenological approach. The Journal of Tolooebehdasht 2019.

[18] Nikkhah H, Fadaei S. The study of economic, sociocultural and psychological needs of the disabled people. Journal of Hormozgan Cultural Research Review 2016;5(10):29-45.

[19] Nikbakht A, Bastami A, Tabrizi NK, et al. Exploring homebased rehabilitation in traumatic spinal cord injury patients: a qualitative study. Iranian J Nurs Res 2017;11(6):32-40.

[20] Rasa AR, Hosseini SA, Haghgoo HA, et al. Aspects related to resilience in people with spinal cord injury. Archives of Rehabilitation 2016;17(4):350-9.

[21] Tagaki M. Long-term experiences of men with spinal cord injuries in Japan: a qualitative study. Forum Qualitative Sozialforschung / Forum: Qualitative Social Research 2015;16(2).

[22] Barari B, Ghaffari M. Mental health of physically disabled persons compare to the normal people: Investigation based on the psychopathology and positive psychology approaches. MEJDS 2015;5(11):281-8.

[23] Ebadollahi H, Piri A, Narbin MM. Stigma and social identity: the case of individuals with visible physical disabilities in Rasht. Iranian Journal of Social Problems 2012;2(1):195-222.

[24] Naderifar M, Tafreshi ZM, Ilkhani M, et al. The outcomes of stress exposure in hemodialysis patients. J Renal Inj Prev 2017;6(4):275-81. 